\title{
Application of auriculotemporal nerve block and dextrose prolotherapy in exercise therapy of TMJ closed lock in adolescents and young adults
}

Hongzhi Zhou ${ }^{1,2^{*}}$ D, Yang Xue ${ }^{1,2}$ and Ping Liu ${ }^{1,2}$

\begin{abstract}
Background: Temporomandibular joint (TMJ) 'closed lock' is a clinical condition causing TMJ pain and limited mouth opening (painful locking). Recent studies suggest an increasing prevalence of degenerative joint disease associated with the onset of TMJ closed lock in adolescents and young adults. Early interventions are recommended, but the curative effect of standard therapies remains controversial. In this retrospective study, an alternative method of non-surgical treatment of TMJ closed lock is presented, and its long-term efficacy has been observed.
\end{abstract}

Methods: Forty adolescents and young adults, aged 16 to 30 years old, with distinct combination of symptoms of TMJ closed lock, were enrolled. Patients received anesthetic blockages of the auriculotemporal nerve, then performed mandibular condylar movement exercise for $10 \mathrm{~min}$, and subsequently received hypertonic dextrose prolotherapy in retro-discal area of TMJ. Clinical assessments at baseline and at follow-up (2 weeks, 2 months, 6 months, and 5 years) included intensity and frequency of TMJ pain, mandibular range of motion, TMJ sounds, and impairment of chewing.

Results: Cone beam CT images of the TMJs revealed joint space changes in all patients and degenerative bone changes in 20\% (8/40) of the patients. The patients were diagnosed as having disc displacement without reduction with limited opening. Successful reduction of displaced disc had been achieved in the treatment. And pain at rest and pain on mastication had substantially decreased in all patients and mandibular function and mouth opening had significantly improved since 2 weeks' follow-up. The overall success rate kept at a high level of 97.5\% (39/40) at 6 months and 5 years' follow-up.

Conclusions: The technique combining mandibular condylar movement exercise with auriculotemporal nerve block and dextrose prolotherapy is straightforward to perform, inexpensive and satisfactory to young patients with TMJ closed lock.

Keywords: Temporomandibular joint, Closed lock, Disc displacement without reduction, Degenerative joint disease, Exercise therapy, Hypertonic dextrose prolotherapy

\footnotetext{
* Correspondence: hongzhi.zhou@foxmail.com; hzzhou@fmmu.edu.cn

'State Key Laboratory of Military Stomatology, National Clinical Research Center for Oral Diseases, Shaanxi Clinical Research Center for Oral Diseases, 145\# Western Changle Road, Xi'an 710032, P.R. China

${ }^{2}$ Department of Oral and Maxillofacial Surgery, School of Stomatology, The

Fourth Military Medical University (FMMU), Xi'an 710032, China
}

C C The Author(s). 2021 Open Access This article is licensed under a Creative Commons Attribution 4.0 International License, which permits use, sharing, adaptation, distribution and reproduction in any medium or format, as long as you give appropriate credit to the original author(s) and the source, provide a link to the Creative Commons licence, and indicate if changes were made. The images or other third party material in this article are included in the article's Creative Commons licence, unless indicated otherwise in a credit line to the material. If material is not included in the article's Creative Commons licence and your intended use is not permitted by statutory regulation or exceeds the permitted use, you will need to obtain permission directly from the copyright holder. To view a copy of this licence, visit http://creativecommons.org/licenses/by/4.0/ The Creative Commons Public Domain Dedication waiver (http://creativecommons.org/publicdomain/zero/1.0/) applies to the data made available in this article, unless otherwise stated in a credit line to the data. 


\section{Background}

Temporomandibular joint (TMJ) closed lock is a clinical condition that is mostly attributed to anterior or anteromedial disc displacement without reduction (DDwoR). DDwoR can be a quite debilitating intra-articular disorder, causing significant pain and dysfunction that disturbs the patient's quality of life with the potential for persistence of symptoms and degenerative joint diseases (DJD) [1-8]. The possible mechanism for jaw locking and DDwoR progression has been proposed to begin as a displaced disc obstructing the forward condylar translation, and direct mechanical injury from joint overloading and hypoxia-reperfusion injury would result in release of free radicals into the synovial fluid causing degradation of hyaluronic acid and eventually a vacuum effect (suction cup effect). The end result of these proposed pathological processes leads to anchored disc phenomenon, and degenerative progression in the longer term [1-3].. Recent studies suggest an increasing frequency of degenerative TMJ changes in adolescents and young adults, which is associated with recent-onset TMJ closed lock. Therefore, early interventions are strongly recommended for symptomatic young patients to minimize the possibility of DJD and dento-maxillofacial consequences [8-10].

In view of therapeutic effects, and risks and costs associated with more complex interventions, patients with symptomatic TMJ closed lock should be initially treated by the least invasive intervention focusing at speeding up the process of alleviation of pain and of improvement in mouth opening [1, 3, 11-15]. The most commonly applied methods of closed lock conservative management include: education and counseling, mandibular manipulation, splint therapy, exercise therapy and pharmacotherapy [12-16]. Validity of therapeutic exercise has been mostly supported by studies from the viewpoint of evidence-based medicine. The standard therapy includes self-exercise with or without additional jaw manipulation, cognitive-behavioral therapy, and education for TMD [14-17]. However, the type of exercise and manual technique differ among researchers, and the treatment effect is easily affected by pain level and locking duration. Patients generally need to take analgesic drugs for weeks, perform mandibular condylar exercise and/or wear splints for months. The reduction of signs and symptoms of TMJ closed lock seems to be related more to the passage of time, but not to the exercise. Further, some long-term survey data indicate that temporomandibular dysfunction remains a recurrent or persistent condition in $50 \%$ of symptomatic patients diagnosed with TMD even after successful physical therapy $[4-7,18-20]$.

By contrast, in designing this study we scheduled anesthetic block of auriculotemporal nerve to numb
TMJ area before exercise procedures. The regional anesthesia can reduce pain and protective muscle splinting, increase the mandibular range of motion, and assist in providing a more manageable treatment [21, 22]. Afterwards, hypertonic dextrose prolotherapy targeting retro-discal tissues was used to rehabilitate ligaments or tendons that compose the posterior band. The hypothesis were: sufficient exercise could produce stretching forces to overcome the vacuum effect of the displaced disc and result in full reduction of the disc in one treatment, furthermore, strengthening of the posterior band junction could help prevent recurrence of anterior displacement of the disc. Long-term observation was conducted to evaluate the clinical efficacy of the method in the management of TMJ closed lock adolescents and young adults $[23,24]$.

\section{Materials and methods \\ Patients}

Forty patients (16-30 years old) were enrolled between Jun 2014 and Jun 2015. All these patients had undergone conservative treatment before this procedure, but did not respond to the same. All the patients and/or their patients gave their informed consent for the treatment. They were assessed clinically and radiographically by a senior oral surgeon. The clinical diagnosis criteria for TMJ closed lock were: joint clicking followed by sudden onset of pain and limited mouth opening without clicking; joint pain and limitation in jaw opening severe enough to interfere with ability to eat; a painful locking duration over a week; history of recurrent lock. Cone beam computed tomography (CBCT) images of the TMJs were obtained and evaluated in consecutive slices. The exclusion criteria were: less than 16 years of age, inability to understand the treatment; history of psychoses; maxillomandibular developmental abnormality.

\section{Treatment procedure}

Firstly, the patients received anesthetic blockages of the auriculotemporal nerve with injections of $2 \mathrm{ml} \mathrm{2 \%}$ lidocaine without vasoconstrictor. The injection method was as follows: (1) mandibular condyle was palpated to find the condylar neck for introduction of anesthesia while patients were instructed to open and close the mouth; (2) then the patients were asked to close the mouth and keep in a resting position; (3) a 35-mm-long and 0.5$\mathrm{mm}$-diameter needle was inserted about $6 \mathrm{~mm}$ anterior to the junction of the tragus and lobule and directed to the lateral bone surface of the condylar neck to deposit $0.5 \mathrm{ml}$ lidocaine; (4) the needle was penetrated around the backside of condyle and into the posterior periarticular tissues to a depth of about $25-28 \mathrm{~mm}$ where $1.0 \mathrm{ml}$ lidocaine was deposited; (5) the needle was gradually withdrawn meanwhile the final $0.5 \mathrm{ml}$ lidocaine was 
deposited. Figure 1 shows the injection point for the patient.

Secondly, the patients were guided to perform mandibular condylar movement exercise to achieve sufficient recovery of the mouth-opening in about $10 \mathrm{~min}$. The exercise consisted of repetitive and incremental mouth opening and bi-lateral movement of the mandibular jaw. Patients could use their fingers to pull down on lower tooth while opening the jaw to the greatest extent, or exercise maximum mouth opening and maximum tongue protrusion. Successful reduction of displaced disc was indicated by returning of joint clicking during mandibular condylar movement exercise, and recovery of mouth opening up to $35-\mathrm{mm}$ width. Figure 2 shows the maximum mouth opening before and after the exercise.

Finally, the patients received injection of $2 \mathrm{ml} 50 \%$ dextrose as proliferation therapy (prolotherapy) in retrodiscal area. Because the auriculotemporal nerve runs around the mandibular condyle's neck and passes through the retro-discal site of TMJ. The dextrose prolotherapy injection were designed to use the same method as described above in anesthetic blockages of auriculotemporal nerve. Patients were advised to use NSAIDs as well as local application of ice in following days for possible post-treatment pain.

\section{Analyses}

Clinical examinations and questionnaires were completed at baseline and at 2 weeks, 2 months, 6 months follow-ups, and a telephone survey was made at 5 years. The effectiveness of treatment was assessed using outcome measures recommended by the International Association of Oral and Maxillofacial Surgeons (IAOMS). Data collection included pain intensity and frequency, jaw range of motion, TMJ sounds, and mandibular function impairment [11]. All complications during any of the treatments were recorded. Post-treatment CBCT studies of the TMJs were performed at 6 months.

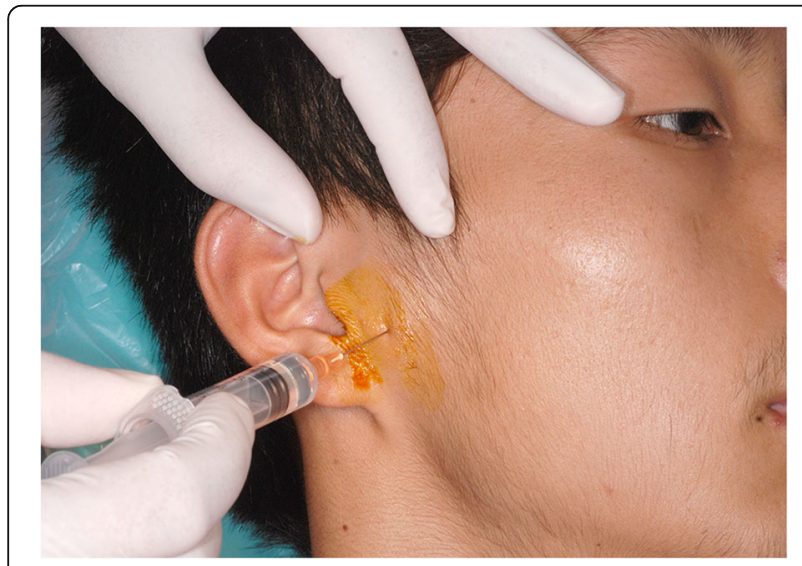

Fig. 1 The figure shows the injection point for the patient
Success criteria consisted of the disappearance of or very mild arthralgia, mouth opening of more than $35 \mathrm{~mm}$, and the ability to eat a normal diet [6]. Statistical analysis of the evaluation parameters was performed using Microsoft Excel.

\section{Results}

The initial CBCT image of TMJs revealed joint space changes in all patients and degenerative bone changes in $20 \%(8 / 40)$ of the patients before the treatment. Patients were diagnosed according to the Diagnostic Criteria for Temporomandibular Disorders (DC/TMD) as having disc displacement without reduction with limited opening (Axis I Group IIb), and DDwoR with concomitant degenerative joint disease (Group IIb/IIIb). The clinical characteristics of the study population are given in Table 1.

Under auriculotemporal nerve block, patients could have their displaced disc reduced by self-exercise in the treatment. Significant improvement of pain at rest and pain on mastication were reported two weeks after the treatment. Dull pain due to injection of hypertonic dextrose was reported and could be alleviated effectively by oral analgesics $(0.8 \pm 2.3$ tablets/per patient) in the first two days. Slight numbness at the injection site was reported by $6 / 40$ patients $(15.0 \%)$ and recovered within a week.

Analyses of IAOMS recommended outcome variables by time effect are shown in Table 2. The mandibular function and mouth opening basically returned to normal since then and kept in a stable condition from 2 weeks to 6 months follow-up. Only one patient claimed mouth opening limitation (maximum opening $30 \mathrm{~mm}$ ) and asked for splint therapy at two months follow-up, who was then classified as unsuccessful case. Four patients requested additional injections for further stabilization of the joint at 6 months, and 2 patients requested additional injections in contralateral joint at 6 months and 5 years. The overall success rate kept at a high level of $97.5 \%(39 / 40)$ at 6 months and 5 years' follow-up.

The follow-up CBCT images confirmed more ideal articular fossa-condyle relationship. The dominant location of affected condyles changed from a posterior position to a media position in all patients. Condylar repair was also observed in patients with degenerative joint disease. No progressed condylar bone destruction or condyle deformation were observed. Figure 3 shows the pre- and post-treatment CBCT images of the TMJs.

\section{Discussion}

This study was designed to confirm the clinical efficacy of an alternative method of conservative treatments for TMJ closed lock in adolescents and young adults. We 


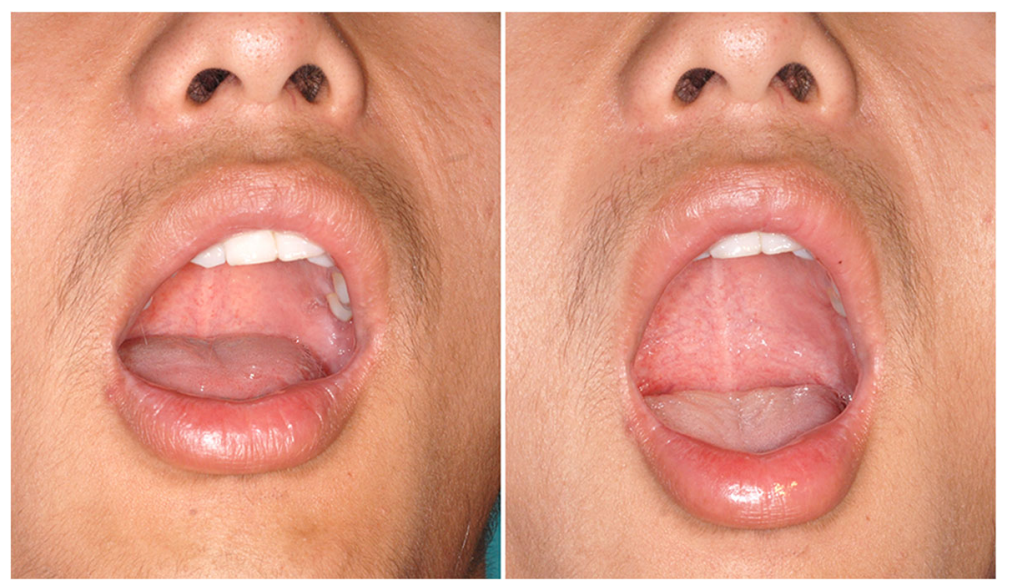

Fig. 2 The figures show the maximum mouth opening before and after the mandibular condylar movement exercise

innovatively combined mandibular condylar movement exercise with auriculotemporal nerve block and dextrose prolotherapy to improve curative effects. The technique is unique, to the best of our knowledge, in that TMJ closed lock reduction and reinforced articular disc repositioning could be accomplished in one conservative treatment. The therapeutic process is greatly simplified and shortened.

As the recommendations of the International RDC/ TMD Consortium Network (2014), the episode of TMJ "closed lock" has good diagnostic validity for the disc displacement without reduction with limited opening (ie, sensitivity 80\%; specificity 97\%) [25]. Distinct combination of symptoms could be observed in these patients: previous clicking of the TMJ; limitation of mouthopening immediately after the joint had stopped clicking; oro-facial pain at rest and at mastication; limitation of lateral movement away from the affected side; and deviation of the mandible to the affected side on opening the mouth [3]. In this study, the symptoms combination has been used as strict inclusion criteria. The enrolled patients all have the typical indications for acute TMJ closed lock. A relief of more severe symptoms can be more persuasive evidence for the curative effects of the treatment. And patients' willingness to accept therapies that can achieve rapid results are fairly strong.

Lei J, et al. reported that the prevalence of degenerative TMJ changes could be up to $59.30 \%$ in chinses adolescents and young adults with recent-onset disc displacement without reduction [9]. Most of these degenerative changes were early-stage osteoarthritic (OA) changes, including loss of continuity of the articular cortex and surface erosion or destruction identified by high-resolution $\mathrm{CBCT}$. Late-stage OA changes (deviation in form and osteophyte) occurred in $13.63 \%$ of the symptomatic TMJs. This is basically consistent with the findings of this study, where $20 \%(8 / 40)$ of the DDwoR patients also presented with degenerative joint disease. Adolescents and young adults may be particularly vulnerable to consequences of degenerative joint disease since normal condylar formation could be hindered [26]. Early diagnosis and intervention is thus prudent to improve the possibility of condylar repair and regeneration to restore TMJ form/structure in adolescents/young adults [27].

TMJ closed lock start from "mechanical" joint disorder, in which a displaced disc obstructs the forward condylar translation resulting in restricted mouth opening [3]. Theoretically, mandibular condylar movement exercise could overcome the interference of displaced discs and increase condylar mobility. However, patients' attempts to increase mouth-opening were frequently hindered by the pain of TMJ. Without enough exercise range, the mandibular condylar movement might displace the disc gradually farther forward to an anterior position. Then the increased mouth opening would be a result of adaptive condylar movement over deformed disc [17]. In fact, a number of studies have reported that

Table 1 The clinical characteristics of the study population

\begin{tabular}{llll}
\hline $\begin{array}{l}\text { RDC/TMD } \\
\text { Axis I Group }\end{array}$ & $\begin{array}{l}\text { Age distribution } \\
\leq \mathbf{2 0} / \mathbf{2 1 - 2 5} / \mathbf{2 6 - 3 0}\end{array}$ & Gender (F/M) & $\begin{array}{l}\text { Time since first episode of } \\
\text { TMJ close lock } \\
\text { (Months, mean } \pm \text { SD) }\end{array}$ \\
\hline Group IIb & $10 / 16 / 7$ & $25 / 7$ & $7.56 \pm 8.65$ \\
Group IIb/lllb & $2 / 5 / 1$ & $8 / 0$ & $14.14 \pm 8.85$ \\
\hline
\end{tabular}


Table 2 Follow-up of IAOMS recommended variables and additional injections

\begin{tabular}{|c|c|c|c|c|c|c|}
\hline & & Base line & 2 weeks & 2 months & 6 months & 5 years \\
\hline \multirow[t]{2}{*}{ Vertical range of motion } & $<35 \mathrm{~mm}$ & 40 & 5 & 4 & 1 & 1 \\
\hline & $\geq 35 \mathrm{~mm}$ & 0 & 35 & 36 & 39 & 39 \\
\hline \multirow[t]{2}{*}{ Lateral and protrusive movement } & $<6 \mathrm{~mm}$ & 27 & 2 & 1 & 1 & 1 \\
\hline & $\geq 6 \mathrm{~mm}$ & 13 & 38 & 39 & 39 & 39 \\
\hline \multirow[t]{2}{*}{ Impaired mandibular function } & Yes & 40 & 4 & 2 & 1 & 1 \\
\hline & No & 0 & 36 & 38 & 39 & 39 \\
\hline \multirow[t]{2}{*}{ Excessive joint pain frequency } & Yes & 40 & 5 & 4 & 1 & 1 \\
\hline & No & 0 & 35 & 36 & 39 & 39 \\
\hline \multirow[t]{2}{*}{ Excessive joint pain intensity } & Yes & 40 & 3 & 2 & 1 & 1 \\
\hline & No & 0 & 37 & 38 & 39 & 39 \\
\hline \multirow[t]{2}{*}{ Joint clicking } & Yes & 0 & 0 & 2 & 7 & 7 \\
\hline & No & 40 & 40 & 38 & 33 & 33 \\
\hline \multirow{3}{*}{$\begin{array}{l}\text { Additional injections for enhancement } \\
\text { of curative effect }\end{array}$} & \multicolumn{2}{|l|}{ Group IIb } & 0 & 0 & 1 & 0 \\
\hline & \multicolumn{2}{|c|}{ Group IIb/lllb } & 0 & 0 & 3 & 0 \\
\hline & \multicolumn{2}{|c|}{ Contralateral joint } & 0 & 0 & 1 & 1 \\
\hline
\end{tabular}

disc recapturing by regular exercise is very limited. In more than $75 \%$ of the successfully treated cases, discs are still anteriorly displaced and deformed [13, 28]. The betterment of function based on adaptive disc deformity is not a stable condition. There are risks of progression to the more advanced stages by a breakdown in the balance between a patient's adaptive capacity and overloading of the TMJ. Temporomandibular dysfunction might become a recurrent or persistent condition for a long time [4-7].
Anesthetic block of auriculotemporal nerve can effectively numb TMJ and reduce protective muscle splinting $[21,22]$. Subsequently, patients can quickly increase the range of jaw movement through pain-free exercise in several minutes. Meanwhile, sufficient condylar movement produces enough stretching forces on the displaced disc to exceed the anchoring forces produced by vacuum effect, and result in full reduction of the disc. The presence of an audible TMJ click during mandibular
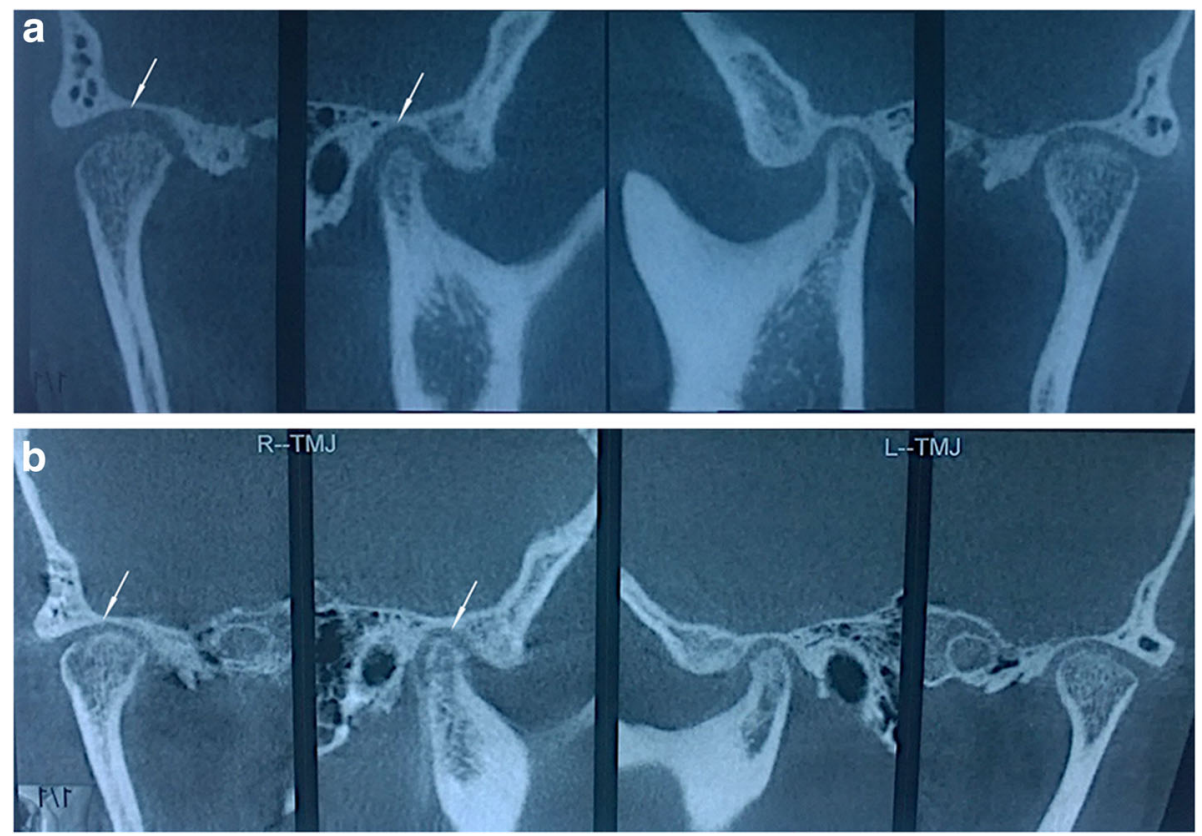

Fig. 3 The figures show the pre- (a) and post-treatment (b) CBCT images of the TMJs 
condylar movement exercise has been reported by patients in this study, and has been proved an indication for successful TMJ closed-lock reduction [26, 29]. Physical disc reduction in the early course of closed lock is important, because the disc position is not likely to change in long-standing internal derangement [2-4]. Also, an ideal disc-condyle relationship appears extremely important for condylar repair and regeneration in adolescence or young patients with TMJ DJD [26].

When the disc is recaptured through excise therapy, a considerable number of cases will be re-dislocated [14, 26]. We designed hypertonic dextrose prolotherapy to stabilize the repositioning of the disc. Fouda, A.A. has reported that injection of hypertonic dextrose in retrodiscal area is effective for reducing clicking and subsequently improving TMJ derangement [23]. Dextrose is considered to be the safest proliferating agent as it is soluble in water, a normal constituent of blood chemistry, and can be injected in large quantities without complications. Hypertonic dextrose solutions at the injection site dehydrate cells, which leads to inflammation of local tissue that in turn triggers the release of growth factors such as fibroblast growth factor, and connective tissue growth factor [30, 31]. The growth factors initiate fibroblast proliferation with production of stronger, thicker, and organized connective tissue [32,33]. Tissue repair can be evident at 2 weeks with fibrosis and other signs of regeneration at the injection sites [33]. Strengthening of ligaments or tendons that compose the posterior band would prevent anterior displacement of articular disc and also result in a tight feeling in posterior area of affected joint, which would spectacularly diminish without further treatments.

\section{Conclusions}

The technique combining mandibular condylar movement exercise with auriculotemporal nerve block and dextrose prolotherapy is straightforward to perform, inexpensive and satisfactory to young patients with TMJ closed lock. Limitations of this study include a relatively small sample size. Larger and randomized controlled trials are required to further determine whether all TMJ closed lock patients respond similarly to the treatment.

\section{Acknowledgements}

I would like to express my gratitude to all those who helped me during the writing of this thesis.

\section{Authors' contributions}

Hongzhi Zhou, performed the clinical therapy and wrote the manuscript; Yang Xue, contributed significantly to analysis and manuscript preparation; Ping Liu, contributed significantly to data collection and analysis. The author(s) read and approved the final manuscript.

\section{Authors' information}

All authors are affiliated with the Department of Oral and Maxillofacial Surgery, School of Stomatology, State Key Laboratory of Military
Stomatology, National Clinical Research Center for Oral Diseases, Shaanxi Clinical Research Center for Oral Diseases, The Fourth Military Medical University (FMMU),

\section{Funding}

Not applicable.

\section{Availability of data and materials}

The data sets supporting the results of this article are included within the article.

\section{Declarations}

\section{Ethics approval and consent to participate}

The study was approved by the Ethics Committee at the School of Stomatology, the Fourth Military Medical University. All participants gave informed consent. This retrospective study involved no more than minimal risk to subjects, did not adversely affect the rights and welfare of subjects, contributed to greater public good, and could not practically be carried out otherwise.

\section{Consent for publication}

Informed consent for publication was obtained from all participants.

\section{Competing interests}

There are no actual or potential conflict of interest needs to be disclosed, including any financial, personal or other relationships with other people or organizations that could inappropriately influence, or be perceived to influence, their work.

Received: 23 December 2020 Accepted: 11 March 2021

Published online: 27 March 2021

\section{References}

1. Al-Baghdadi M, Durham J, Araujo-Soares V, Robalino S, Errington L, Steele J. TMJ disc displacement without reduction management: a systematic review. J Dent Res. 2014;93(7 Suppl):37S-51S.

2. Al-Baghdadi M, Durham J, Steele J. Timing interventions in relation to temporomandibular joint closed lock duration: a systematic review of 'locking duration'. J Oral Rehabil. 2014;41(1):24-58.

3. Nitzan DW, Marmary Y. The "anchored disc phenomenon": a proposed etiology for sudden-onset, severe, and persistent closed lock of the temporomandibular joint. J Oral Maxillofac Surg. 1997;55(8):797-802 discussion 802-3.

4. Roh HS, Kim W, Kim YK, Lee JY. Relationships between disk displacement, joint effusion, and degenerative changes of the TMJ in TMD patients based on MRI findings. J Craniomaxillofac Surg. 2012;40(3):283-6.

5. Imirzalioglu P, Biler N, Agildere AM. Clinical and radiological follow-up results of patients with untreated TMJ closed lock. J Oral Rehabil. 2005;32(5): 326-31.

6. Murakami K, Kaneshita S, Kanoh C, Yamamura I. Ten-year outcome of nonsurgical treatment for the internal derangement of the temporomandibular joint with closed lock. Oral Surg Oral Med Oral Pathol Oral Radiol Endod. 2002;94(5):572-5.

7. Louw WF, Reeves KD, Lam SKH, Cheng AL, Rabago D. Treatment of Temporomandibular dysfunction with hypertonic dextrose injection (Prolotherapy): a randomized controlled trial with long-term partial crossover. Mayo Clin Proc. 2019;94(5):820-32.

8. de Paiva Bertoli FM, Bruzamolin CD, de Almeida Kranz GO, Losso EM, Brancher JA, de Souza JF. Anxiety and malocclusion are associated with temporomandibular disorders in adolescents diagnosed by RDC/TMD. A cross-sectional study. J Oral Rehabil. 2018;45(10):747-55.

9. Lei J, Han J, Liu M, Zhang Y, Yap AU, Fu KY. Degenerative temporomandibular joint changes associated with recent-onset disc displacement without reduction in adolescents and young adults. J Craniomaxillofac Surg. 2017;45(3):408-13.

10. Zhuo Z, Cai X, Xie Q. Is anterior disc displacement without reduction associated with temporomandibular joint condylar height in juvenile patients younger than 20 years? J Oral Maxillofac Surg. 2015;73(5):843-9.

11. Schiffman EL, Velly AM, Look JO, Hodges JS, Swift JQ, Decker KL, Anderson QN, Templeton RB, Lenton PA, Kang W, Fricton JR. Effects of four treatment 
strategies for temporomandibular joint closed lock. Int J Oral Maxillofac Surg. 2014;43(2):217-26.

12. Miernik M, Więckiewicz W. The basic conservative treatment of Temporomandibular joint anterior disc displacement without reduction-review. Adv Clin Exp Med. 2015;24(4):731-5.

13. Naeije M, Te Veldhuis AH, Te Veldhuis EC, Visscher CM, Lobbezoo F. Disc displacement within the human temporomandibular joint: a systematic review of a 'noisy annoyance'. J Oral Rehabil. 2013;40(2):139-58.

14. Nagata K, Maruyama H, Mizuhashi R, Morita S, Hori S, Yokoe T, Sugawara Y Efficacy of stabilisation splint therapy combined with non-splint multimodal therapy for treating RDC/TMD axis I patients: a randomised controlled trial. J Oral Rehabil. 2015;42(12):890-9.

15. Nagata K, Hori S, Mizuhashi R, Yokoe T, Atsumi Y, Nagai W, Goto M. Efficacy of mandibular manipulation technique for temporomandibular disorders patients with mouth opening limitation: a randomized controlled trial for comparison with improved multimodal therapy. J Prosthodont Res. 2019; 63(2):202-9.

16. Ismail F, Demling A, Hessling K, Fink M, Stiesch-Scholz M. Short-term efficacy of physical therapy compared to splint therapy in treatment of arthrogenous TMD. J Oral Rehabil. 2007:34(11):807-13.

17. Haketa T, Kino K, Sugisaki M, Takaoka M, Ohta T. Randomized clinical trial of treatment for TMJ disc displacement. J Dent Res. 2010;89(11):1259-63.

18. Craane B, Dijkstra PU, Stappaerts K, De Laat A. Randomized controlled trial on physical therapy for TMJ closed lock. J Dent Res. 2012;91(4): 364-9.

19. Minakuchi H, Kuboki T, Matsuka Y, Maekawa K, Yatani H, Yamashita A. Randomized controlled evaluation of non-surgical treatments for temporomandibular joint anterior disk displacement without reduction. J Dent Res. 2001;80(3):924-8.

20. Armijo-Olivo S, Pitance $L$, Singh $V$, Neto $F$, Thie N, Michelotti A. Effectiveness of manual therapy and therapeutic exercise for Temporomandibular disorders: systematic review and meta-analysis. Phys Ther. 2016;96(1):9-25.

21. DuPont JS Jr. Simplified anesthesia blocking of the temporomandibular joint. Gen Dent. 2004;52(4):318-20.

22. Donlon WC, Truta MP, Eversole LR. A modified auriculotemporal nerve block for regional anesthesia of the temporomandibular joint. J Oral Maxillofac Surg. 1984;42(8):544-5.

23. Fouda AA. Change of site of intra-articular injection of hypertonic dextrose resulted in different effects of treatment. Br J Oral Maxillofac Surg. 2018; 56(8):715-8

24. Kino K, Ohmura Y, Amagasa T. Reconsideration of the bilaminar zone in the retrodiskal area of the temporomandibular joint. Oral Surg Oral Med Oral Pathol. 1993;75(4):410-21.

25. Schiffman E, Ohrbach R, Truelove E, et al. International RDC/TMD consortium network, international association for dental research; Orofacial pain special interest group, International Association for the Study of Pain. Diagnostic criteria for Temporomandibular disorders (DC/TMD) for clinical and research applications: recommendations of the international RDC/TMD consortium network* and Orofacial pain special interest groupt. J Oral Facial Pain Headache. 2014;28(1):6-27.

26. Lei J, Yap AU, Liu MQ, Fu KY. Condylar repair and regeneration in adolescents/young adults with early-stage degenerative temporomandibular joint disease: a randomised controlled study. J Oral Rehabil. 2019;46(8):704-14.

27. Yoshida H, Kashiwagi K, Sakata T, Tanaka M, Kawazoe T, Morita S. Prognostic factor of mandibular condylar movement exercise for patients with internal derangement of the temporomandibular joint on initial presentation: preliminary report. J Craniomaxillofac Surg. 2013;41(5):356-8.

28. Ohnuki T, Fukuda M, Nakata A, Nagai H, Takahashi T, Sasano T, Miyamoto Y. Evaluation of the position, mobility, and morphology of the disc by MRI before and after four different treatments for temporomandibular joint disorders. Dentomaxillofac Radiol. 2006;35(2):103-9.

29. Murakami Kl, lizuka T, Matsuki M, Ono T. Recapturing the persistent anteriorly displaced disk by mandibular manipulation after pumping and hydraulic pressure to the upper joint cavity of the temporomandibular joint. Cranio. 1987:5(1):17-24.

30. Creaney L, Hamilton B. Growth factor delivery methods in the management of sports injuries: the state of play. Br J Sports Med. 2008;42(5):314-20.
31. Yoshii Y, Zhao C, Schmelzer JD, Low PA, An KN, Amadio PC. Effects of hypertonic dextrose injections in the rabbit carpal tunnel. J Orthop Res. 2011;29(7):1022-7.

32. Yoshii Y, Zhao C, Schmelzer JD, Low PA, An KN, Amadio PC. Effects of multiple injections of hypertonic dextrose in the rabbit carpal tunnel: a potential model of carpal tunnel syndrome development. Hand (N Y). 2014; 9(1):52-7.

33. Dagenais S, Mayer J, Wooley JR, Haldeman S, Hite M. Acute toxicity evaluation of proliferol: a dose-escalating, placebo-controlled study in rats. Int J Toxicol. 2007;26(5):451-63.

\section{Publisher's Note}

Springer Nature remains neutral with regard to jurisdictional claims in published maps and institutional affiliations.
Ready to submit your research? Choose BMC and benefit from:

- fast, convenient online submission

- thorough peer review by experienced researchers in your field

- rapid publication on acceptance

- support for research data, including large and complex data types

- gold Open Access which fosters wider collaboration and increased citations

- maximum visibility for your research: over $100 \mathrm{M}$ website views per year

At BMC, research is always in progress.

Learn more biomedcentral.com/submissions 